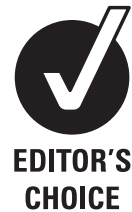

\section{See Editorial, p 434}

${ }^{1}$ Centre of Expertise for Health and Work Ability, Finnish Institute of Occupational Health, Helsinki, Finland

${ }^{2}$ The National Institute of Health and Welfare, Helsinki, Finland ${ }^{3}$ Centre of Expertise for Good Practices and Competence, Finnish Institute of Occupational Health, Helsinki, Finland

\section{Correspondence to} Dr Helena Miranda, Finnish Institute of Occupational Health, Helsinki, Topeliuksenkatu 41 a A, 00250 Helsinki, Finland helena.miranda@ttl.fi

Accepted 19 October 2009

\title{
Musculoskeletal pain at multiple sites and its effects on work ability in a general working population
}

\author{
Helena Miranda, ${ }^{1}$ Leena Kaila-Kangas, ${ }^{1}$ Markku Heliövaara, ${ }^{2}$ Päivi Leino-Arjas, \\ Eija Haukka, ${ }^{1}$ Juha Liira, ${ }^{3}$ Eira Viikari-Juntura ${ }^{1}$
}

\section{ABSTRACT}

Objectives Musculoskeletal pain often occurs at multiple sites concurrently. The aim of this study was to examine the associations between multi-site pain and self-rated work ability and retirement plans among actively working people.

Methods The Health 2000 Survey was carried among a representative sample of Finnish adults.

Musculoskeletal pain during the preceding month in the lower back, neck or shoulders, upper extremities, hips and lower extremities, and work ability and intentions to retire early were assessed. Subjects were also clinically examined. Analyses were restricted to 30-64-year-old subjects actively working during the preceding 12 months who provided information on work ability outcomes (population-weighted number of subjects=4087). Log-binomial regression was used to estimate prevalence ratios of reduced work ability.

Results Single-site pain was reported by $33 \%$ of subjects, 20\%, 9\% and 4\% reported pain in two, three and four sites, respectively, and $8 \%-15 \%$ reported poor work ability. Every fifth person had thought about retiring early. Age- and gender-adjusted risks of poor physical work ability and own prognosis of poor future work ability increased from 2 for single-site pain to 8 for pain at four sites. Risks remained considerably elevated after adjustment for various covariates, including clinical musculoskeletal disorders and functional capacity. Poor current work ability was most affected by multi-site pain at older age (50-64 years) and intentions to retire early at age $40-49$ years.

Conclusions Co-occurring pain is a considerable threat to work ability. Workers with multi-site pain may benefit from targeted preventive measures to sustain their work ability. Future studies should also consider multi-site pain as an important risk factor for reduced work ability.

\section{INTRODUCTION}

Several recent population-based studies have shown that people often have pain at several body sites concurrently. ${ }^{1-3}$ In some studies, multi-site pain has been more frequently reported than singlesite pain. ${ }^{1}$ Consequently, two recent editorials of a leading pain research journal have suggested that the basic expectation should be that one local pain accompanies another, irrespective of pain site. ${ }^{4} 5$ This brings a new perspective to epidemiological research on musculoskeletal disorders, which has traditionally focused on assessing pain at a single site, most often in the lower back, and ignored the presence of pain at other sites.

The consequences of multi-site pain seem to be worse than those of single-site pain. In a population

\section{What this paper adds}

Pain at multiple sites concurrently is a common phenomenon among working people.

- Multi-site pain poses a considerable threat to work ability.

- Future studies should consider multi-site pain as an important risk factor for reduced work ability.

- Multi-site pain should be screened for and given special attention, for example. in health checkups organised by occupational health services.

- Workers with multi-site pain may benefit from better targeted preventive measures in order to sustain their ability to work.

study with a 4-year follow-up, localised low back pain alone did not predict long-term work disability, but when low back pain was part of a widespread pain condition, a significant increase in the disability risk was found. ${ }^{6}$ In another study, problems in functioning, measured with physical fitness, feelings, daily activities and social activities, increased almost linearly with the increasing number of pain sites, whereas experiencing singlesite pain did not have an impact on functional status. ${ }^{1}$ Also, other studies have reported widespread pain affecting everyday functioning and quality of life..$^{7-9}$

Several studies on multi-site pain and work ability have measured work ability in terms of sick leave or disability pension. ${ }^{10-13}$ Although these outcomes are objective and valid, they are also always tied to the current social security system used by the particular country or employer. Selfrating of work ability is less prone to the effect of existing social benefits and therefore more suitable for cross-study comparisons. Work ability can be assessed by people themselves, and these assessments are relatively robust predictors of future disability. $^{14-17}$ A recent systematic review ${ }^{18}$ summarised the individual and work-related determinants of work ability and showed that poor musculoskeletal capacity is related to poorer work ability measured with the Work Ability Index (WAI) ${ }^{15}$ Pain as such was not included in the review. ${ }^{18}$ Although there is evidence that pain has a strong and immediate causal effect on work ability, ${ }^{19}$ little is known of the effect of multi-site pain on self-rated work ability. The aim of this population-based study was to investigate whether the number of pain sites is associated with selfrated work ability and plans to retire early. 


\section{METHODS}

\section{Study subjects and design}

A national health examination survey was carried out between autumn 2000 and spring 2001 in Finland. ${ }^{20}$ The main emphasis of this Health 2000 Survey was to obtain up-to-date information from Finnish adults on cardiovascular, respiratory, musculoskeletal and mental diseases and related disability, treatments and risk factors. The survey consisted of several questionnaires, an extensive home interview, laboratory and functional capacity tests, and clinical examination. ${ }^{21}$ The nationally representative population sample of Finnish adults (30 years or older) was formed using a two-stage cluster sampling method whereby Finland was stratified into 20 strata, that is, the 15 biggest cities and five university hospital districts. The 15 cities and 65 of the 234 municipalities or groups of municipalities with joint primary care (within the five university hospital districts) drawn by systematic sampling, formed the 80 clusters. A total of 8028 persons aged 30-99years were originally sampled from the clusters. The study population in this paper consisted of 30-64year-old participants who were actively working during the preceding 12 months.

\section{Outcomes}

The five outcomes in this study were self-rated ability to work (four features) and plans to retire early. The home interview included questions on perceived current work ability with respect to the physical demands of work (outcome I) and with respect to the mental demands of work (outcome II). The response options 'good or very good' were classified as 0 (reference category) and 'moderate, poor or very poor' as 1. Future work ability was assessed with two questions: own prognosis of work ability 2 years from now (outcome III: $0=$ will improve or remain stable; $1=$ will deteriorate) and ability to continue working with regard to health issues in the same job for the next 2 years (outcome IV: $0=$ rather certain; $1=$ don't think so or not sure). Outcomes I-III were items derived from the validated WAI. ${ }^{15}$ Retirement plans (outcome V) were assessed with the question: Have you thought about retiring early, before the age of the old-age pension? $(0=$ no; $1=$ sometimes or often).

\section{Determinant}

The main determinant was the number of anatomical sites with pain. The subjects were asked in an interview whether they had experienced pain in the neck or shoulders, low back, upper extremities, and hips or lower extremities during the preceding month (no/yes). Pain in the shoulders, hips and extremities included right, left or both sides. A pain variable with five categories was constructed $(0=$ no pain to $4=$ pain in all four sites).

\section{Covariates}

Covariates included in the analyses were chosen based on literature and prior knowledge. More detailed descriptions of the variables have been published elsewhere. ${ }^{21}$ The demographic factors were age, gender, education (years) and marital status. Body mass index (BMI, $\mathrm{kg} / \mathrm{m}^{2}$ ) was based on height and weight measured in the clinical examination. Smoking (never, ex-, current smoker) was assessed during the face-to-face interview, and physical exercise (times per week, for at least $30 \mathrm{~min}$ ) with a questionnaire. Of the work-related factors, physical work load was assessed in the interview with questions about being exposed to any of the following for more than half of the daily work time: lifting, carrying, working in awkward postures, with a hand above shoulder level, on one's knees or in a squatting position, using repetitive hand motions, or forceful hand activities. Psychosocial factors included psychological demands at work (five items from the Job Content Questionnaire, JCQ), job control (eight items from the JCQ) and social support at work (supervisor and co-worker support, four items from the $\mathrm{JCO}^{22}$ ), as well as job insecurity (five items). ${ }^{23}$

Of the health-related factors assessed by interview and the questionnaires, the following variables were included in the analyses: somatisation (Symptom Checklist; sum index of 10 items, three pain-related items excluded), ${ }^{24}$ self-rated health (one item), ${ }^{25}$ psychological well-being (General Health Questionnaire: sum index of 12 items) ${ }^{26}$ and sleep problems (one question from the 15-Dimension Quality of Life questionnaire). ${ }^{27}$ Somatic diseases (cardiovascular, respiratory, etc) and musculoskeletal disorders were diagnosed by the examining physician. ${ }^{28}$ Self-perceived functional capacity was assessed during the interview with the following questions on six activities: Are you able (nowadays) to run a long distance (about half a kilometre); run a short distance (about $100 \mathrm{~m}$ ); climb several flights of stairs without resting; climb one flight of stairs without resting; walk about $2 \mathrm{~km}$ without resting; or walk about half a kilometre without resting? The response categories for each item were: without difficulty; with minor difficulty; with major difficulty; and not at all. ${ }^{29}$ A sum index was formed from these items.

\section{Data analyses}

The associations between the main independent variable and the outcomes were estimated with log-binomial regression, and if the log-binomial model failed to converge, the COPY method was used. ${ }^{30}$ Risks are presented as prevalence ratios (PRs) with 95\% CIs. The covariates had to be related to both the outcome and the main independent variable to be included in the modelling. All covariates except smoking and physical activity fulfilled this criterion. Due to the cross-sectional design, modelling was performed in several steps. First, the regression models were adjusted for age and gender. Second, those covariates which were considered as least likely to lie on the causal pathway between the independent and dependent variable, were included in the models. These variables were education, marital status, physical work load, BMI and somatic diseases. The third step in the modelling included psychosocial work-related factors and tendency for somatisation. The last step included variables that were potentially on the causal pathway, that is, clinically diagnosed musculoskeletal disorders, psychological well-being, sleep problems, self-perceived health and functional capacity. The purpose of also adjusting for these possible intermediate variables was to estimate the independent effect of multi-site pain on the work ability outcomes, regardless of the presence of, for example, a clinical musculoskeletal disorder or reduced functioning.

Effect modification by age and gender was investigated with stratified analyses. Since the proportion of missing values was less than $10 \%$ for the main independent variable as well as covariates, complete participant analyses were performed. ${ }^{31}$ The distributions of the outcomes, main independent variable and covariates both among subjects included in and excluded from the multivariable models are presented separately to demonstrate that no selection bias due to missing values occurred, and, for example, multiple imputations for various covariates were not needed. The population weighting was used to correct the age, sex, living district and language distributions of the sample to correspond with those of the Finnish population. Statistical analyses were performed with SAS v 9.2. 


\section{RESULTS}

The study population consisted of 30-64-year-old subjects $(\mathrm{n}=5871)$, of whom $88 \%(\mathrm{n}=5152)$ participated in the interview and $83 \%(n=4886)$ attended the health examination. In the present study, the analyses were restricted to subjects who were actively working during the preceding 12 months and who provided complete information on the work ability outcomes (population-weighted number of subjects=4087).

Among these 4087 subjects, poor work ability with respect to physical work demands was reported by 636 subjects $(16 \%)$ and poor work ability with respect to the mental demands of work by 556 subjects (14\%). A total of 542 subjects (13\%) estimated that their work ability will deteriorate during the next 2 years, and 332 subjects (8\%) estimated that they will not be able to continue working due to health issues in the same job for the next 2 years. Women and men did not differ regarding these outcomes. Only retirement plans differed slightly between the genders: $21 \%$ of the women and $16 \%$ of the men had often thought about retiring early before the old-age pension (18\% of all subjects, $n=745$ ). The distributions of poor current and future work ability and retirement plans are presented in table 1 and by age group in figure 1 .

One third of subjects had musculoskeletal pain in one site only during the preceding month, while $20 \%, 9 \%$ and $4 \%$ had pain in two, three and four sites, respectively. Multi-site pain increased the risk of poor physical work ability: the age- and gender-adjusted PR was 1.9 (95\% CI 1.4 to 2.6) for those with single-site pain, increasing to 6.0 (95\% CI 4.6 to 7.8 ) for four pain sites (table 2). After stepwise adjustment for various covariates, the risks remained considerably elevated for those with multi-site pain. The PRs for poor mental work ability were generally lower than those for poor physical work ability (table 2).

Pain had a strong association with the participant's own prognosis of work ability in the next 2 years measured with two separate questions. Even in the 'over-adjusted' models, the risks were two times higher for those with four pain sites when compared to those without pain. Multi-site pain also increased the possibility of having early retirement plans. Gender did not modify the effect of the number of pain sites on the work ability outcomes.

Age modified the effect of pain on poor physical work ability and retirement plans. In the middle age group (40-49 years), pain at four sites increased the risk of poor physical work ability. In the oldest age group, there was an almost threefold increase in the risk even after adjustment for all possible covariates (figure 2). The number of pain sites increased the likelihood of having plans to retire early mainly among those aged $40-49$ years (figure 3).

Table 1 Background characteristics of the participants included in and excluded from the analyses based on missing values, aged 30-64, who held a job during the preceding year (weighted proportion)

\begin{tabular}{|c|c|c|c|c|}
\hline & \multicolumn{2}{|c|}{$\begin{array}{l}\text { Subjects included in the } \\
\text { multivariable analyses (no } \\
\text { missing values in any of the } \\
\text { covariates), } n=3137\end{array}$} & \multicolumn{2}{|c|}{$\begin{array}{l}\text { Subjects excluded from the } \\
\text { multivariable analyses } \\
\text { (missing values in one or more } \\
\text { covariates), } n=618-950\end{array}$} \\
\hline \multicolumn{5}{|l|}{ Individual factors } \\
\hline \multicolumn{5}{|l|}{ Age (years) } \\
\hline $30-39$ & 1056 & 34 & 306 & 32 \\
\hline Female gender & 1512 & 48 & 473 & 50 \\
\hline Low education (maximum 9 years) & 607 & 19 & 250 & 26 \\
\hline Severely overweight or obese $(\mathrm{BMI} \geq 28)$ & 959 & 31 & 318 & 35 \\
\hline Psychological symptoms & 647 & 21 & 182 & 24 \\
\hline Somatisation & 280 & 9 & 90 & 13 \\
\hline Mild or severe sleep problems & 1394 & 44 & 284 & 46 \\
\hline \multicolumn{5}{|l|}{ Work-related factors } \\
\hline Physically demanding work & 1259 & 40 & 441 & 47 \\
\hline Job insecurity & 672 & 22 & 140 & 23 \\
\hline Psychosocial demands at work (scale $5-25$ ), mean (SD) & $16(4)$ & & $16(4)$ & \\
\hline Job control (scale 8-40), mean (SD) & $31(6)$ & & $31(6)$ & \\
\hline Social support at work (scale 2-10), mean (SD) & $8(2)$ & & $8(2)$ & \\
\hline \multicolumn{5}{|l|}{ Number of musculoskeletal pain sites } \\
\hline 0 & 1031 & 33 & 245 & 33 \\
\hline 1 & 1050 & 33 & 234 & 32 \\
\hline 2 & 648 & 21 & 143 & 19 \\
\hline 3 & 288 & 9 & 78 & 10 \\
\hline 4 & 120 & 4 & 43 & 6 \\
\hline
\end{tabular}




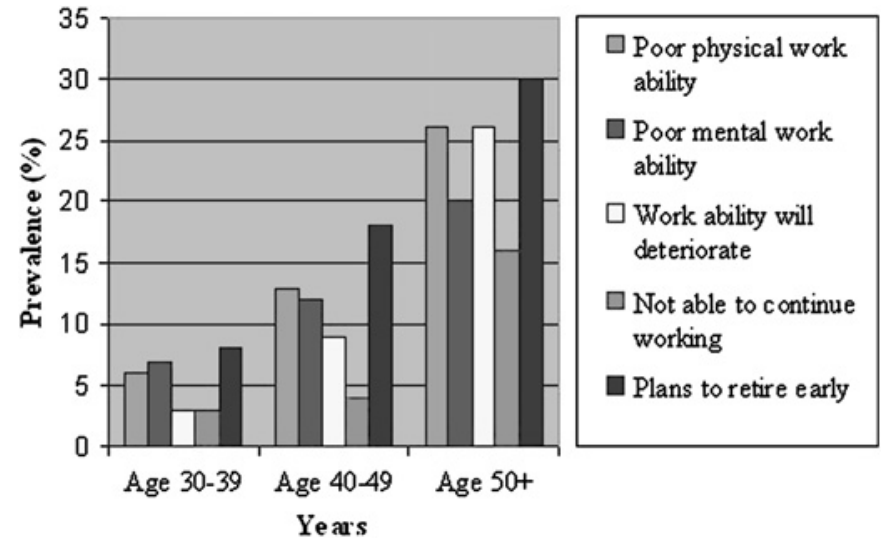

Figure 1 The distribution of poor current and future work ability and retirement plans by age group.

\section{DISCUSSION}

In this study among a representative sample of actively working Finnish adults, pain at multiple body sites was strongly associated with self-perceived work ability. Those with multi-site pain considerably more often perceived their current work ability to be poor compared to those with no pain or only single-site pain. Also, they estimated more frequently that their work ability will deteriorate and that they may not be able to continue working in the same job. They also had more often thought about retiring early.

Approximately every sixth subject reported that his or her current work ability was not good, while slightly fewer subjects predicted that they would have difficulties in maintaining their work ability in the near future. Early retirement was being considered by every fifth worker. Our findings support the results from earlier population-based studies from Finland showing that a considerable proportion of workers report 'nongood' work ability. ${ }^{15} 32$ Our results showing that men and women perceive their work ability to be approximately the same, as well as age having a strong effect on work ability, are also consistent with earlier studies. ${ }^{15} 32-34$

The main determinant of interest in this study was the number of concurrent pain sites. The finding that pain in more than one site was as prevalent as single-site pain is in accordance with other studies. ${ }^{1}$ A recent study suggests that multi-site pain is a relatively stable phenomenon: the average number of pain sites appears set by age 20 and little variation occurs after that. ${ }^{53}$ This is also supported by our study in which age did not show any consistent association with the number of pain sites (data not shown).

The risk of reporting poor work ability as well as early retirement plans was notably higher among those with multi-

Table 2 Adjusted risks of poor work ability by number of pain sites

\begin{tabular}{|c|c|c|c|c|c|c|c|c|c|c|}
\hline \multirow{3}{*}{$\begin{array}{l}\text { No. } \\
\text { of } \\
\text { pain } \\
\text { sites }\end{array}$} & \multicolumn{10}{|c|}{ Work ability outcomes } \\
\hline & \multirow{2}{*}{$\begin{array}{l}\text { No. of } \\
\text { references }\end{array}$} & \multirow{2}{*}{$\begin{array}{l}\text { No. of } \\
\text { cases }\end{array}$} & \multicolumn{2}{|c|}{ Model 1* } & \multicolumn{2}{|c|}{ Model 2† } & \multicolumn{2}{|c|}{ Model 3‡ } & \multicolumn{2}{|c|}{ Model 4§ } \\
\hline & & & PR & $95 \% \mathrm{CI}$ & PR & $95 \% \mathrm{CI}$ & PR & $95 \% \mathrm{Cl}$ & PR & $95 \% \mathrm{CI}$ \\
\hline & \multicolumn{10}{|c|}{ Poor physical work ability } \\
\hline 0 & 966 & 65 & 1.0 & & 1.0 & & 1.0 & & 1.0 & \\
\hline 1 & 929 & 121 & 1.9 & 1.4 to 2.6 & 1.8 & 1.4 to 2.4 & 1.8 & 1.4 to 2.4 & 1.5 & 1.1 to 1.9 \\
\hline 2 & 529 & 119 & 2.8 & 2.1 to 3.7 & 2.5 & 1.9 to 3.3 & 2.3 & 1.8 to 3.1 & 1.7 & 1.3 to 2.2 \\
\hline 3 & 199 & 89 & 4.5 & 3.4 to 5.9 & 3.6 & 2.7 to 4.8 & 2.7 & 2.0 to 3.6 & 1.7 & 1.3 to 2.3 \\
\hline \multirow[t]{2}{*}{4} & 60 & 60 & 6.0 & 4.6 to 7.8 & 3.9 & 2.9 to 5.3 & 3.1 & 2.3 to 4.2 & 1.9 & 1.4 to 2.6 \\
\hline & \multicolumn{10}{|c|}{ Poor mental work ability } \\
\hline 0 & 938 & 92 & 1.0 & & 1.0 & & 1.0 & & 1.0 & \\
\hline 1 & 929 & 121 & 1.3 & 1.0 to 1.7 & 1.3 & 1.0 to 1.7 & 1.3 & 1.0 to 1.6 & 1.1 & 0.8 to 1.6 \\
\hline 2 & 558 & 90 & 1.5 & 1.2 to 2.0 & 1.5 & 1.1 to 1.9 & 1.2 & 0.9 to 1.6 & 0.9 & 0.6 to 1.4 \\
\hline 3 & 229 & 59 & 2.1 & 1.6 to 2.8 & 2.0 & 1.5 to 2.7 & 1.4 & 1.0 to 1.9 & 1.0 & 0.6 to 1.6 \\
\hline \multirow[t]{2}{*}{4} & 78 & 43 & 3.4 & 2.5 to 4.7 & 2.9 & 2.1 to 3.9 & 1.6 & 1.1 to 2.3 & 1.3 & 0.7 to 2.3 \\
\hline & \multicolumn{10}{|c|}{ Work ability will deteriorate } \\
\hline 0 & 968 & 63 & 1.0 & & 1.0 & & 1.0 & & 1.0 & \\
\hline 1 & 944 & 106 & 1.7 & 1.3 to 2.2 & 1.6 & 1.2 to 2.2 & 1.6 & 1.2 to 2.2 & 1.4 & 1.1 to 1.9 \\
\hline 2 & 542 & 106 & 2.4 & 1.8 to 3.2 & 2.3 & 1.7 to 3.1 & 2.2 & 1.6 to 2.9 & 1.8 & 1.3 to 2.4 \\
\hline 3 & 216 & 72 & 3.3 & 2.4 to 4.5 & 2.8 & 2.0 to 3.8 & 2.5 & 1.8 to 3.4 & 1.7 & 1.2 to 2.4 \\
\hline \multirow[t]{2}{*}{4} & 66 & 54 & 4.5 & 3.4 to 6.0 & 3.9 & 2.8 to 5.3 & 3.1 & 2.2 to 4.2 & 2.3 & 1.6 to 3.3 \\
\hline & \multicolumn{10}{|c|}{ Not able to continue working } \\
\hline 0 & 1002 & 29 & 1.0 & & 1.0 & & 1.0 & & 1.0 & \\
\hline 1 & 996 & 54 & 2.0 & 1.3 to 3.0 & 1.8 & 1.2 to 2.8 & 1.8 & 1.2 to 2.8 & 1.5 & 1.0 to 2.2 \\
\hline 2 & 581 & 67 & 3.5 & 2.3 to 5.4 & 3.0 & 2.0 to 4.6 & 2.7 & 1.8 to 4.1 & 1.9 & 1.2 to 2.8 \\
\hline 3 & 241 & 47 & 5.1 & 3.3 to 7.8 & 3.8 & 2.4 to 5.8 & 2.7 & 1.6 to 4.3 & 1.8 & 1.1 to 2.7 \\
\hline \multirow[t]{2}{*}{4} & 82 & 38 & 7.9 & 5.2 to 12.1 & 5.2 & 3.3 to 8.2 & 3.3 & 2.0 to 5.4 & 2.0 & 1.3 to 3.1 \\
\hline & \multicolumn{10}{|c|}{ Thought about retiring early } \\
\hline 0 & 892 & 138 & 1.0 & & 1.0 & & 1.0 & & 1.0 & \\
\hline 1 & 886 & 164 & 1.2 & 1.0 to 1.5 & 1.2 & 1.0 to 1.4 & 1.1 & 0.9 to 1.4 & 1.1 & 0.9 to 1.3 \\
\hline 2 & 530 & 118 & 1.4 & 1.1 to 1.7 & 1.3 & 1.0 to 1.6 & 1.2 & 1.0 to 1.5 & 1.1 & 0.8 to 1.3 \\
\hline 3 & 188 & 101 & 2.4 & 1.9 to 2.9 & 2.1 & 1.7 to 2.7 & 1.8 & 1.4 to 2.2 & 1.5 & 1.2 to 2.0 \\
\hline 4 & 73 & 47 & 2.5 & 2.0 to 3.2 & 2.3 & 1.7 to 3.0 & 1.8 & 1.4 to 2.4 & 1.5 & 1.1 to 2.0 \\
\hline
\end{tabular}

Prevalence ratios (PR) with 95\% Cls)

* Model 1: adjusted for age and gender.

†Model 2: Model 1+education, marital status, physical work load, body mass index and somatic disease.

¥Model 3: Model 2+psychological demands of work, job control, social support, job insecurity and somatisation.

§Model 4: model 3+clinically diagnosed musculoskeletal disorder, psychological well-being (General Health Questionnaire), sleep problems, self-perceived health and functional capacity. 


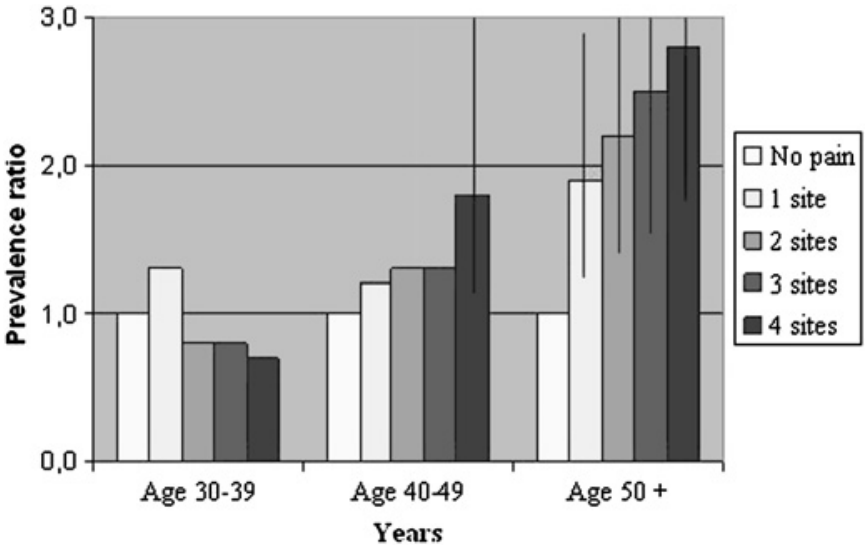

Figure 2 The risk of reporting poor current work ability in respect of the physical demands of work, by the number of pain sites and by age group (prevalence ratios*, vertical lines present $95 \%$ Cls not including unity). *Adjusted for gender, education, marital status, physical work load, body mass index, somatic disease, psychological demands of work, job control, social support, job insecurity, somatisation, clinically diagnosed musculoskeletal disorder, psychological well-being, sleep problems, self-perceived health and functional capacity.

site pain compared to those with localised pain or without any pain. Age- and gender-adjusted prevalence ratios were high at up to 8 . Since the data were based on an extensive health survey, we were able to further adjust the relationships with various selfreported and more objectively measured covariates. We were able to examine most factors that, based on the literature, are related to work ability and pain and hence could confound the associations between the two. Kamaleri and others recently published a paper showing that multi-site pain predicted disability pension for any health reason 14 years later. In their study, self-rated health and sick leave during the previous year captured almost all the predictive power of the number of pain sites regarding work disability. ${ }^{35}$ In our study, the risks of decreased work ability still remained elevated after self-rated health was included in the analyses. Prior sick leaves, although measured,

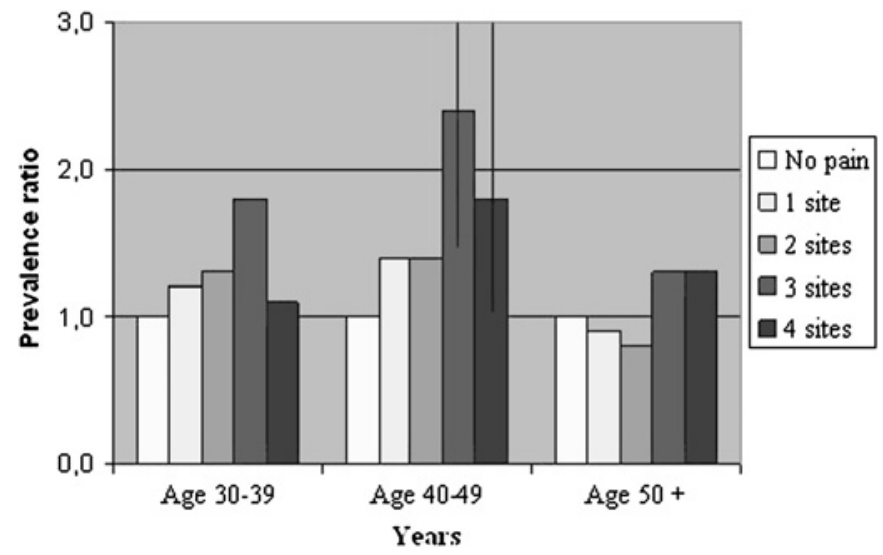

Figure 3 The risk of reporting early retirement plans by the number of pain sites and by age group (prevalence ratios*, vertical lines present $95 \%$ Cls not including unity). ${ }^{*}$ Adjusted for gender, education, marital status, physical work load, body mass index, somatic disease, psychological demands of work, job control, social support, job insecurity, somatisation, clinically diagnosed musculoskeletal disorder, psychological well-being, sleep problems, self-perceived health and functional capacity. were not included in the main analyses since they are likely to be a consequence of self-rated poor work ability. Additional adjustment for prior sick leaves did not affect the results (data not shown).

Many studies have shown that women have higher rates of sickness absence and disability pensions due to musculoskeletal disorders. ${ }^{36}$ However, our study did not indicate that the effect of multi-site pain on self-perceived work ability was stronger for women than for men. Other studies on multi-site pain predicting these more objective outcomes have not reported gender-specific results. ${ }^{10-13}$ Therefore, more studies are needed to investigate whether the higher prevalence of multi-site pain explains the higher rates of musculoskeletal disorder-specific sickness absence and disability among women.

Age modified the effect of pain on physical work ability and retirement plans. Most of the effect of multi-site pain on poor physical work ability occurred among the oldest workers $(50+$ years). The associations among the youngest workers (30-39 years) were almost completely captured by somatisation in the model, that is, the tendency to express personal and social distress through physical symptoms, such as fatigue, nausea, breathing difficulties or a lump in the throat. ${ }^{24} 37$ Somatisation has been shown to predict chronic widespread pain. ${ }^{38}$ In our study, almost half of those with four pain sites, and $25 \%$ of those with three pain sites were 'somatisers', whereas only $3 \%$ $6 \%$ of those with no or one pain site belonged to this group. It should be noted, however, that more than half of the subjects with pain in four sites were not somatisers, indicating that multi-site pain is not just a manifestation of somatisation. The associations between pain and retirement plans occurred mainly in the middle age group (40-49 years). The reason for this could be that Finns retire relatively early (on average at the age of 59 years) and among the older workers (50+ years), factors other than pain, such as somatic diseases, may become more important determinants of retirement.

Pain at multiple sites affects work ability through various possible mechanisms, for instance clinical diseases giving rise to pain, such as rheumatoid arthritis, and in some cases decreased fitness as a consequence of a disease-related reduction in physical activity. In our study, however, even after adjustment with factors such as clinically diagnosed musculoskeletal disorders or reduced functional capacity, which can be seen as mediators of the effect of multi-site pain on work ability, the risks remained increased twofold for most outcomes. This implies that pain per se is a strong and immediate determinant of work ability. A mechanism potentially important from a preventive viewpoint is that widespread pain changes the subject's experience of time, as a recent qualitative study among chronic widespread pain patients demonstrated. ${ }^{39}$ First, the time needed to complete everyday tasks increases, and second, the ability to sustain tasks for any length of time decreases. Reduced control over time among pain sufferers should be considered in future workrelated disability research, particularly because time, or rather the lack of it, is a dominant feature in many workplaces. For example, in 2005, 26\% of the workforce in the European Union reported having to work at very high speed all or almost all of the time. ${ }^{40}$ Work intensity has increased considerably in EU countries during the past two decades. ${ }^{40}$

This study has several strengths. The original study sample represents the entire population aged 30 years and older in Finland. The participation rate was very good with $83 \%-88 \%$ of the working age subjects taking part. Most items in the questionnaires, face-to-face interview and health examination protocols were selected on the basis of standardised, generally 
accepted recommendations, or nationally established practice. ${ }^{21}$ Work ability questions were taken mainly from the validated and internationally recognised WAI. ${ }^{15}$ The WAI and its items have been shown to reliably predict work disability, retirement and mortality. ${ }^{16}$ We decided not to use the entire validated WAI which has seven items, since two of the items (the number of current diseases diagnosed by a physician, and estimated work impairment due to diseases) already included information on diseases such as musculoskeletal disorders, and the number of musculoskeletal pain sites would have correlated with such an outcome variable. Further, our aim was to investigate whether the effect of multi-site pain on self-perceived work ability differed with respect to the physical or mental demands of work. Therefore, these two items were chosen as outcome variables, instead of the item on overall work ability (current work ability compared with lifetime best). Moreover, regarding the very high rates of sick leaves and disability pensions due to musculoskeletal disorders, it was important from a preventive perspective to also examine whether multi-site pain has longerterm consequences on work ability in addition to affecting current work ability. With outcome variables such as the workers' own prognosis of the future development of work ability as well as their early retirement plans, we were able to examine this issue in this cross-sectional study.

Pain in various anatomical sites was assessed for the preceding month. The 1-month prevalence question was also used in the previous large population-based health examination survey, the Mini-Finland Study 20 years earlier, and it has been commonly used in other studies, particularly in Europe. ${ }^{41}$ Many studies have defined multi-site pain based on symptoms occurring in several body sites over a much longer time period, most often 12 months. ${ }^{35}$ The shorter the time period to assess symptoms, the more accurately they are recalled, the more likely the symptoms in different body sites are truly concurrent and the better they fit into the definition of multi-site pain. Moreover, the large sample size allowed us to include a wide variety of possible confounders and intermediate variables in the analyses. ${ }^{42}$ Hence, the observed associations are unlikely due to confounding by unmeasured factors of major importance.

The main limitation in this study is the cross-sectional study design: the independent and dependent variables were measured at the same time and hence the true temporal order cannot be established. However, it seems unlikely that poor current work ability or poor prognosis of future work ability would have caused pain in multiple body sites. It is possible that some subjects have a reporting behaviour that leads to a higher reporting both of adverse health symptoms and of the consequences of these symptoms, such as poorer work ability. As a result, the associations between pain and work ability would be overestimated. However, since these subjects report more physical symptoms overall, not only those pain-related, adjustment for somatisation at least partly reduced the effect of this phenomenon. ${ }^{37}$ Despite the lack of temporal evidence in our study, most findings support the causal relationship between multi-site pain and reduced work ability because of the strength of the associations with dose-response effects, alternative explanations being unlikely, plausible mechanisms, and agreement with current knowledge according to which multi-site pain has worse consequences than single-site pain.

\section{CONCLUSIONS}

To our knowledge, this is the largest population-based study showing a graded association between multi-site pain and selfrated work ability among those still actively at work. Our results add to the increasing body of evidence arguing that epidemiological research that concentrates on localised pain without assessing other pain sites will inevitably be of limited value. Future studies should also consider multi-site pain as an important risk factor for reduced work ability. It can be concluded that the co-occurrence of pain poses a considerable threat to the ability to continue working, especially among the older workforce. Hence, multi-site pain should be screened for and given special attention, for example, in health check-ups organised by occupational health services. Workers with multisite pain may benefit from better targeted preventive measures in order to help sustain their ability to work.

\section{Competing interests None.}

Ethics approval This study was conducted with the approval of the Helsinki University Ethics Committee.

Provenance and peer review Not commissioned; externally peer reviewed.

\section{REFERENCES}

1. Kamaleri Y, Natvig B, Ihlebaek CM, et al. Localized or widespread musculoskeletal pain: does it matter? Pain 2008;138:41-6.

2. Markkula R, Järvinen $P$, Leino-Arjas $P$, et al. Clustering of symptoms associated with fibromyalgia in a Finnish Twin Cohort. Eur J Pain 2008;13:744-50.

3. Schmidt C0, Baumeister SE. Simple patterns behind complex spatial pain reporting? Assessing a classification of multi-site pain reporting in the general population. Pain 2007:133:174-82

4. Croft P, Dunn KM, Von Korff M. Chronic pain syndromes: you can't have one without another. Pain 2007;131:237-8

5. Croft $\mathbf{P}$. The question is not "have you got it"? But "how much of it have you got"? Pain 2009;141:6-7

6. Natvig B, Eriksen W, Bruusgaard D. Low back pain as a predictor of long-term work disability. Scand J Public Health 2002;30:288-92.

7. Natvig B, Rutle 0 , Bruusgaard D, et al. The association between functional status and the number of sites in the body with musculoskeletal symptoms. Int $\mathrm{J}$ Rehabil Res 2000:23:49-53.

8. Nordin M, Hiebert R, Pietrek M, et al. Association of comorbidity and outcome in episodes of nonspecific low back pain in occupational populations. J Occup Environ Med 2002;44:677-84.

9. Saastamoinen $\mathbf{P}$, Leino-Arjas $\mathrm{P}$, Laaksonen $\mathrm{M}$, et al. Pain and health related functioning among employees. J Epidemiol Community Health 2006:60:793-98.

10. IJzelenberg W, Burdorf A. Impact of musculoskeletal co-morbidity of neck and upper extremities on healthcare utilisation and sickness absence for low back pain. Occup Environ Med 2004;61:806-10.

11. Kamaleri Y, Natvig B, Ihlebaek CM, et al. Number of pain sites is associated with demographic, lifestyle, and health-related factors in the general population. Eur J Pain 2008; 12:742-8.

12. Morken T, Riise T, Moen B, et al. Low back pain and widespread pain predict sickness absence among industrial workers. BMC Musculoskelet Disord 2003:4:21.

13. Nyman T, Grooten WJ, Wiktorin C, et al. Sickness absence and concurrent low back and neck-shoulder pain: results from the MUSIC-Norrtälje study. Eur Spine $J$ 2007; 16:631-8.

14. Alavinia SM, de Boer AG, van Duivenbooden JC, et al. Determinants of work ability and its predictive value for disability. Occup Med (Lond) 2009;59:32-7.

15. Ilmarinen J, Tuomi K, Klockars M. Changes in the work ability of active employees over an 11-year period. Scand J Work Environ Health 1997;23(Suppl 1): 49-57.

16. IImarinen J, Tuomi K. Past, present and future of work ability. People and work research reports. Helsinki: Finnish Institute of Occupational Health, 2004;65:1-25.

17. Liira J, Matikainen $E$, Leino-Arjas $P$, et al. Work ability of middle-aged Finnish construction workers - a follow-up study in 1991-1995. Int J Ind Ergon 2000;25:477-81.

18. van den Berg TI, Elders $L A$, de Zwart $B C$, et al. The effects of work-related and individual factors on the Work Ability Index: a systematic review. Occup Environ Med 2009;66:211-20.

19. Kapteyn A, Smith JP, van Soest A. Dynamics of work disability and pain. J Health Econ 2008;27:496-509.

20. Aromaa A, Koskinen S, editors. Health and functional capacity in Finland: Baseline results of the Health 2000 Health examination survey. Helsinki: Publications of the National Public Health Institute B12, 2004

21. Heistaro S, editor. Methodology report. Health 2000 Survey. Helsinki: Publications of the National Public Health Institute B 26, 2008

22. Karasek RA. Job demands, job decision latitude and mental strain: implications for job redesign. Administative Science Quarterly 1979;24:285-308.

23. Virtanen P, Vahtera J, Kivimäki M, et al. Employment security and health. $J$ Epidemiol Community Health 2002;56:569-74.

24. Derogatis LR, Lipman RS, Covi L. SCL-90: an outpatient psychiatric rating scale -preliminary report. Psychopharmacol Bull 1973;9:13-28. 
25. de Bruin AZ, Picavet HSJ, Nossikov A. WHO health interview surveys. Towards international harmonization of methods and instruments. Geneva: WHO Regional Publications, European Series, no 58, 1996.

26. Goldberg D. General Health Questionnaire (GHO-12). Windsor, UK: NFER-Nelson, 1992

27. Sintonen $\mathbf{H}$, Pekurinen M. A fifteen-dimensional measure of health-related quality of life (15D) and its applications. In: Walker S, Rosser R, editors. Quality of life assessment key issues in the 1990s. Dordrecht: Kluwer Academic Publishers, 1992.

28. Kaila-Kangas L, editor. Musculoskeletal disorders and diseases in Finland-results of the Health 2000 Survey. Helsinki: Publications of the National Public Health Institute B 25, 2007.

29. Aromaa A, Heliövaara M, Impivaara 0, et al. Terveys, toimintakyky ja hoidontarve Suomessa. Mini-Suomi-terveystutkimuksen perustulokset. Helsinki: Kansaneläkelaitoksen julkaisuja AL:32, 1989. [English summary: Health, functional capacity and need for care in Finland. Baseline results of the Mini-Finland health examination survey. Helsinki and Turku: Publications of the Social Insurance Institution AL:32, 1989]

30. Deddens JA, Petersen MR. Approaches for estimating prevalence ratios. Occup Environ Med 2008;65:481, 501-6.

31. Barzi F, Woodward M. Imputations of missing values in practice: results from imputations of serum cholesterol in 28 cohort studies. Am J Epidemiol 2004;160:34-45

32. Perkiö-Mäkelä M, Hirvonen M, Elo A-L, et al. Työ ja terveys-haastattelututkimus 2006. Taulukkoraportti (Work and Health Survey 2006. Table report. In Finnish). Helsinki: Finnish Institute of Occupational Health, 2006.

33. Goedhard R, Goedhard W. Work ability and perceived work stress. In: Costa G, Goedhard W, Ilmarinen J, editors. Assessment and promotion of work ability, health and well-being of ageing workers. International Congress Series 1280. Amsterdam: Elsevier, 2005: 79-83

34. Tuomi K, Ilmarinen J, Martikainen R, et al. Aging, work, life-style and work ability among Finnish municipal workers in 1981-1992. Scand J Work Environ Health 1997:23(Suppl 1):58-65.

35. Kamaleri Y, Natvig B, Ihlebaek CM, et al. Change in the number of musculoskeletal pain sites: a 14-year prospective study. Pain 2009;141:25-30.

36. Cote D, Coutu MF. A critical review of gender issues in understanding prolonged disability related to musculoskeletal pain: how are they relevant to rehabilitation? Disabil Rehabil 21 July 2009

37. Winfield JB. Does pain in fibromyalgia reflect somatization? Arthritis Rheum 2001;44:751-3.

38. McBeth J, Macfarlane GJ, Benjamin S, et al. Features of somatization predict the onset of chronic widespread pain: results of a large population-based study. Arthritis Rheum 2001:44:940-6.

39. Richardson JC, Ong BN, Sim J. Experiencing and controlling time in everyday life with chronic widespread pain: a qualitative study. BMC Musculoskelet Disord 2008;9:3.

40. European Foundation for the Improvement of Living and Working Conditions. Fifteen years of working conditions in the EU: charting the trends, EF/06/85. http://www eurofound.europa.eu/pubdocs/2006/85/en/1/ef0685en.pdf (accessed 20 0ctober 2009).

41. Nachemson A. Epidemiology and the economics of low back pain. In: Herkowitz $\mathrm{H}$ Dvorak J, Bell G, et al, eds. The lumbar spine. 3rd edn. Philadelphia: Lippincott Williams \& Wilkins, 2004:3-10.

42. IImarinen J, Tuomi K, Seitsamo J. New dimensions of work ability. In: Costa G, Goedhard W, Ilmarinen J, editors. Assessment and promotion of work ability, health and well-being of ageing workers. International Congress Series 1280. Amsterdam: Elsevier, 2005: 3-7. 